Motrivivência $\quad$ v. $27, \quad$ n. $44, \quad$ p. $207-218$, maio/2015

\title{
CONSIDERAÇÕES SOBRE MÍDIA E “HERÓIS ESPORTIVOS" DO MIXED MARTIAL ARTS
}

Igor Sampaio Pinho Dos Santos?

Vamberto Ferreira Miranda Filho ${ }^{2}$

\section{RESUMO}

O texto tem como objetivo apresentar considerações sobre alguns mecanismos utilizados pela indústria midiática na construção dos "heróis esportivos" do Mixed Martial Arts(MMA). Para tanto, realizou-se um estudo teórico e destacou-se alguns exemplos de situações vividas por atletas brasileiros do MMA, para discutir tais mecanismos. Dessa forma, compreende-se que a espetacularização esportiva, o uso do marketing especializado e o sensacionalismo na veiculação de informações sobre a vida desses atletas, são alguns dos mecanismos utilizados pela mídia na construção dos heróis do MMA. Conclui-se que esta seja uma das estratégias mais eficazes para transformar o MMA num fenômeno popular, fomentando o seu consumo alienado na sociedade brasileira.

Palavras-chave: Mídia; MMA; Heróis Esportivos

1 Licenciado em Educação Física. Pesquisador do grupo GEPEFES-UNEB, Salvador/Bahia, Brasil.

E-mail: isantos.edfisica@gmail.com

2 Mestre em Educação. Professor da UNEB, Salvador/Bahia, Brasil.

E-mail: elgeboh@yahoo.com.br 


\section{INTRODUÇÃO}

"O campeão dos pesos-médios do UFC, Chris Weidman, teve um 'dia de herói' na quinta-feira". "Em dia de super-herói, Chris Weidman salva vizinha de 94 anos" $^{\prime \prime}$. E, assim, destacavam as principais manchetes de jornais e blogs de notícias sobre o MMA, na manhã do dia dezessete de outubro de dois mil e catorze. A notícia logo se espalhou e repercutiu na mídia em todo o mundo.

Segundo o siteMMAFighting.com, o lutador de MMAChris Weidman salvou a vida de uma idosa de 94 anos de idade que acabara de sofrer um acidente doméstico. Até a chegada dos paramédicos, o atleta teve que cuidar sozinho da senhora e mantê-la lúcida até que esta recebesse os devidos atendimentos de emergência. Esse fato repercutiu na imprensa estadunidense e logo se estendeu na mídia internacional, que não hesitou em intitular Weidman como herói. Em outro site de notícias do MMA, o MMASpace, a principal manchete destacava o seguinte: "Dia de Herói: Chris Weidman salva idosa de 94 anos."

Esse e outros fatos semelhantes envolvendo atletas são constantemente evidenciados pelos meios de comunicação de massa (mídia). A indústria midiática cuida imediatamente de dar o "ar da graça" ao enfatizar, com veemência, o fato ocorrido e dar uma pitada de sensacionalismo ao assunto, tornando efetivo o discurso da espetacularização para atrair a atenção do seu público em todo o mundo.

A partir dessa constatação, o objetivo deste texto é apresentar considerações sobre alguns mecanismos utilizados pela mídia na construção dos "heróis esportivos" do MMA, visando, num plano maior, a compreender a contribuição desse processo na popularização deste esporte de combate (MIRANDA FILHO e SANTOS, 2014b) na sociedade brasileira e, consequentemente, seu consumo alienado.

Em que pese ser um dos esportes que mais crescem em evidênciana mídia, ainda há uma escassez de estudos científicos na educação física brasileira que tratem do MMA, justificando a realização deste ensaio.

Desse modo,inicialmente apresentam-se considerações sobre mídia e o processo de mercadorização esportiva na sociedade; na sequência, destacam-se alguns elementos da trajetória de esportivização do vale-tudo até se transformar no MMA; em seguida, discutem-se aspectos da relação entre mídia televisiva e a construção dos "heróis esportivos" do MMA, a partir de exemplos de situações vividas por alguns dos principais atletas brasileiros; e, finalmente, são feitas considerações a partir do objetivo do texto.

\section{Mídia e mercadorização esportiva}

Nas tendências da sociedade capitalista orientadas por relevantes avanços nas

3 Combate.com. Disponível em: http://sportv.globo.com/site/combate/noticia/2014/10/chris-weidman-ajudasalvar-vida-de-vizinha-idosa-em-long-island.html. Acesso em: 17/11/2014.

4 Jornal O Lance!Net, Disponível em: http://www.lancenet.com.br/minuto/super-heroi-Chris-Weidman-salvavizinha_0_1231077039.html. Acesso em: 17/11/2014.

5 Informaçõēes disponíveis no endereço eletrônico: http://www.mmaspace.net/dia-de-heroi-chris-weidman-salva-idosa-de-94-anos-95038/. Acessado em 17/11/2014. 
áreas tecnológicas e de informação e pela instantaneidade como essas informações alcançam seus receptores em várias partes do mundo, a mídia tem exercido um papel determinante estabelecendo saberes, normas sociais e padrões culturais.

De acordo Betti (1998), o termo mídia originou-se do latim media, plural de medium, e que significa "meio". É, segundo o autor, um termo genérico que abarca o conjunto dos meios de comunicação de massa como o rádio, a televisão, os jornais e revistas, e que permite a comunicação simultânea entre um grande número de pessoas.

Pires (2002) acrescenta que a mídia não somente é entendida como os meios de comunicação de massa, mas, também, um grupo de empresas que produz e mercadoriza informações, entretenimento e publicidade. É uma indústria produtora e veiculadora de símbolos e significados socialmente compartilhados na cultura hodierna.

Através de manobras estratégicas, a mídia se configura com grande domínio na sociedade unidirecionando suas mensagens para seus receptores, estabelecendo formas e parâmetros para "universalizar" qualquer manifestação cultural. Na linha de frente, a televisão atua soberana como um dos mais efetivos mecanismos por entreter e influenciar um maior número de pessoas a enxergarem o mundo através de suas lentes, como se fosse uma "janela de vidro" (BETTI, 1998) atuando na produção e disseminação de informações que contemplem os seus interesses.

De fato, a televisão alterou o modo de ser e de viver dos indivíduos e provocou profundos impactos na sociedade, sobretudo no ramo artístico. No capítulo intitulado como "A indústria cultural: o esclarecimento como mistificação das massas", na obra
A Dialética do Esclarecimento, Adorno e Horkheimer (1985) fazem uma série de críticas à sociedade ocidental contemporânea e a existência humana na era capitalista. Segundo esses pensadores, a sociedade está submersa numa nova espécie de barbárie em que a indústria cultural, orientada por ideais liberais e pela globalização do capital, transformou a cultura humana num produto alienado dos homens, em que os meios de comunicação - entendidos como componentes da indústria cultural - atuam determinantes na produção e reprodução da lógica capitalista. Com isso, houve um profundo empobrecimento das artes, a saber: o cinema, o teatro e a música popular, que deveriam apresentar-se como um bem cultural, tornaram-se mercadorias destinadas ao entretenimento das massas e manutenção do status quo.

A televisão é um meio de comunicação que tem se destacado nesse aspecto devido à abrangência como ela alcança as diversas classes sociais, disseminando os produtos da indústria cultural e as ideologias da classe hegemônica. Nesse tocante, a linguagem-imagem da televisão, de acordo Betti (1998, p. 41), "compõe-se de estereótipos que despertam e representam as imagens do inconsciente do telespectador, e assim demonstram como devem comportar-se de acordo com os desejos do sistema".

Apesar de sua obra ter sido publicada na década de 40, Adorno e Horkheimer já analisavam o poder de persuasão da mídia televisiva, mesmo esta não sendo tão difundida nesse período. De acordo esses teóricos, os produtos da indústria cultural submetem os indivíduos a um processo de deformação da sua atividade mental. A televisão, 
nesse caso, incuti uma falsa consciência da realidade, impondo valores, normas e unidirecionando seus conteúdos que, por sua vez, tornam-se únicos na consciência dos sujeitos. "O mundo inteiro é forçado a passar pelo filtro da indústria cultural"(ADORNO e HORKHEIMER, 1985, p. 104).

Nessa perspectiva, a televisão confunde o que é realidade e ilusão, provoca a atrofia da imaginação humana e contribui para a perversão da formação humana ao condicionar a sociedade a comportar-se de acordo as ideologias do sistema capitalista. Orientada por esta lógica, a mídia manipula os indivíduos mediante uma semicultura ${ }^{6} \mathrm{da}$ espetacularização e consumo, construindo uma realidade ilusória que a espontaneidade da sua consciência não consegue perceber.

Não obstante, elemento integrante da cultura humana, o esporte tornou-se o parceiro preferencial da mídia nesse processo e isso é resultante da industrialização e globalização da cultura, tendência que existe desde os primórdios do capitalismo, sendo agora muito mais presente. Conforme a análise de Betti (1998), a televisão é a mídia que mais influencia o esporte e ambos possuem uma relação de interdependência extremamente forte a ponto de a mídia televisiva modificar, significativamente, a maneira como as pessoas percebem e praticam o esporte na atualidade. Orientado por mensagens textuais fragmentadas e unilaterais, que compõem o discurso televisivo, o esporte tornou-se um fenômeno telespetáculo, ou seja, um típico integrante da espetacularização televisiva.
A mobilização social que confere ao esporte o título de fenômeno de grande relevância na atualidade é justificada por Bracht (2005), quando o referido autor menciona que:

Sem dúvida, o esporte faz parte hoje, de uma ou de outra forma, da vida da maioria das pessoas. Tão rápido e tão 'ferozmente' quanto o capitalismo o esporte expandiu-se pelo mundo todo e tornou-se a expressão hegemônica no âmbito da cultura corporal de movimento. Hoje ele é, em praticamente todas as sociedades, uma das práticas sociais que reúne a unanimidade quanto à sua legitimidade social (p. 09).

Dessa forma, a mídia reúne uma gama de conceitos ao esporte na tentativa de induzir o seu consumo, atribuindo-lhe vários sentidos e isso se deve ao fato de haver uma diversidade de interesses que permeiam a sua estrutura, tais como interesses de ordem política, econômica, social e cultural (PIRES, 2002).

Ainda, sobre essa questão, Leite (2008) ressalta que a mídia hoje em dia atua como principal alicerce do sistema capitalista e que, na sua relação com esporte, ela "não está envolvida apenas na sua transmissão, mas também na produção, transformação e ressignificação" (p. 02).

Assim, o esporte atualmente foge da compreensão de consciência e prática corporal, de experiência individual ou coletiva, para se tornar uma prática orientada por

6 Semicultura, ou semiformação cultural, é um termo utilizado por Pires (2002). É a antítese da formação cultural. É a formação negada que sujeita o indivíduo a um estado de minoridade pela manipulação da consciência humana mediante a alienação. É uma lógica hegemônica da classe dominante que obstrui a formação cultural. Entende-se como a falta de esclarecimento, conforme os teóricos da Escola de Frankfurt Adorno e Horkheimer (1985). 
interesses midiatizados funcionando como principal parceiro da indústria do consumo que visa unicamente fins lucrativos. Pires (2002) destaca os altos investimentos dessa indústria e como ela atua na exploração do mercado consumidor, na banalização da cultura esportiva e na sua espetacularização. Dessa forma, o esporte é analisado como a principal tendência da indústria cultural que é a "sua transformação em mercadoria e elemento de colonização do tempo livre dos consumidores" (PIRES, 2002, p. 85).

O processo de "mercadorização" esportiva já era analisado por Betti (1998) como um mecanismo efetivado pelo telespectador que paga para assistir a uma competição esportiva e financia o sistema comercial do esporte. Ainda, de acordo este autor, o esporte tornou-se uma janela de oportunidades para se vender qualquer coisa.

[...] encontramos no anúncio publicitário, condensado em poucos segundos, o espetáculo, a falação, a nostalgia, o cotidiano, a globalização, a velocidade, a ação, a emoção do esporte. Pneu, remédio, cartão de crédito, cerveja, refrigerante, automóvel, pasta dental, correios, leite, assinatura de jornal, flocos de milho, postos de combustível, sorvete, banco, companhia telefônica, perfume, desodorante, papel para xerox, pomada analgésica, televisor, aparelho de som, batata frita, cimento, freios para carro, cigarro, açúcar, canos de PVC. Não são apenas tênis e bolas, o esporte pode vender tudo (BETTI, 1998, p. 171).

Portanto, a banalização da cultura esportiva pela via da mercadorização é consequência de uma ideologia imposta pela mídia na construção dos sentidos/ significados atribuídos ao esporte. A indústria cultural estabelece valores mediante uma semiformação cultural criando falsas necessidades e incorporando estereótipos para que as massas aceitem e reproduzam o que ela quer, em benefício de seu maior interesse: submeter o ser humano a uma condição de consumidor alienado.

\section{$\mathrm{O}$ fenômeno MMA: do vale-tudo à espor- tivização}

Em meio à espetacularização da cultura esportiva pela mídia, surge um novo fenômeno esportivo conhecido como Mixed Martial Artes (MMA), cujo termo,traduzido para o Português, significa Artes Marciais Mistas. Este corresponde à denominação mais recente da prática corporal que, outrora, ficou mundialmente conhecida como Vale-Tudo.

O MMA é um esporte de combate caracterizado pelo emprego de técnicas oriundas de diversas artes marciais. Nesse caso, durante um combate, o seu praticante pode utilizar os inúmeros recursos que a referida prática Ihe disponibiliza. A sua história remete-se ao Vale Tudo, criado no Brasil na década de 1930 pela família Gracie, cujo objetivo foi popularizar a arte marcial difundida pelo clã: o jiu-jjtsu Gracie, também conhecido como brazilian jiu-jitsu Gracie.

A trajetória da família Gracie com o jiu-jitsu iniciou-se no início do século XX, em Belém, capital paraense, quando Gastão Gracie, carioca e descendente de escoceses, conhece EsaiMaeda, também conhecido como Conde Koma, imigrante japonês que acabara de chegar em terras brasileiras. Maeda é acolhido pelos Gracie e, como forma de gratidão, ensina os fundamentos e 
técnicas do jiu-jitsu para os filhos de Gastão, Carlos e Hélio Gracie?

A peregrinação de Conde Koma pelo mundo inspirou os Gracie a se empenharem numa extensa jornada pelo Brasil, desafiando vários lutadores a fim de provar a superioridade do jiu-jitsu frente às demais artes marciais (ALVAREZ e MARQUES, 2011). A popularidade dos irmãos Gracie repercutiu internacionalmente alcançando outros continentes, como a Ásia, e conquistando notoriedade em países de culturas consideradas fechadas, como o Japão. Certamente, nesse período, não havia os mesmos recursos tecnológicos presentes nos dias atuais, de qualquer forma pode-se pressupor que a consolidação do MMA, hoje, deve-se a esse processo de "mundialização" cultural.

Rorion Gracie, filho de Hélio Gracie, é considerado o autor do MMA. Em parceria com um publicitário estadunidense criou, nos Estados Unidos, no ano de 1993, um campeonato de lutas desprovido de regras e intitulado como UltimateFight, hoje conhecido como UltimateFightChampionschip (UFC), que fora pensado como espetáculo a ser veiculado na TV fechada pelo pay-per-view, para popularizar o brazilianjiujitsu Gracie naquele país (MIRANDA FILHO e SANTOS, 2014b). As lutas eram conhecidas como Vale-Tudo, pois não possuíam regras, árbitros, ou tempo. A partir disso, as lutas ganharam notoriedade internacional e ampla publicidade nos Estados Unidos.

Sofrendo pressões políticas devido à violência presente nos combates sem regras, o UFC passou por uma série de mudanças para chegar ao molde atual. O primeiro passo foi a busca pela regulamentação da prática das lutasjunto às comissões atléticas dos Estados Unidos, no início dos anos 2000. Em seguida, aboliu-se o termo Vale-Tudo, que fazia alusão a combates violentos, mudando para Mixed Martial Arts (MMA), quando passou a ter regras bem definidas, tornando-se uma prática corporal esportivizada.

Após a esportivização do MMA, os torneios do UFC foram bem aceitos pela sociedade estadunidense, tornando a referida prática popularizada naquele país e em quase todo o mundo. As transmissões das "lutas do UFC já chegam a 354 milhões de lares em todo o mundo, sendo televisionadas em mais de 145 países e em 19 línguas" (ALVAREZ e MARQUES, 2011, p. 07).

Logo, a esportivização do MMA foi vista como uma alternativa necessária, levando-se em consideração o caráter civilizador presente na implantação das regras. Além disso, é necessário considerar também os fatores econômicos, políticos e ideológicos que permeiam a estrutura do esporte e que marcaram a trajetória do $M M A$, isto é, a intencionalidade dessa esportivização como uma estratégia de viabilizá-lo, ao recuperar os picos de audiência na programação televisiva, restabelecer os altos investimentos e torná-lo o mais novo fenômeno esportivo para atender os interesses dessa indústria do consumo, fomentando a sua espetacularização na sociedade.

7 Os Gracies e o Nascimento do Vale-Tudo (The Graciesandthebirthof Vale Tudo). Direção: Victor Cesar Bota. Produção: Neil L. Postrygacz e Victor Cesar Bota. Roteiro: Victor Cesar Bota. Fotografia: Victor Cesar Bota. Trilha Sonora: Nublu Records. Brasil/Estados Unidos: 2009. DVD (90 min), documentário, colorido. 


\section{Mídia e "heróis esportivos" do MMA}

Na antiguidade, o conceito de herói esteve relacionado a uma narrativa mítica atribuída a um semideus, indivíduo descendente da relação entre uma divindade e um ser humano - concepção platônica. Na modernidade, a ideia do herói foi representada por indivíduos excepcionais, marcados por atos históricos - concepção hegeliana (ABAGGNANO, 2007). Com o desenvolvimento industrial e tecnológico da sociedade contemporânea, o herói tornou-se um estereótipo dos meios de comunicação de massa, isto é, uma construção da indústria cultural(ADORNO e HORKHEIMER, 1985).

Dentre os vários fenômenos que a indústria cultural midiática tem produzido para a emergência de atitudes heroicas, o esporte de alto rendimento tem ocupado um lugar destacado (RUBIO, 2001). O esporte tem a capacidade de refletir a lógica e estrutura da sociedade capitalista por possuir algumas características deste modelo de sociedade.

Em termos ideológicos, o campeão heroico é aquele que trabalhou muito, galgou os degraus da hierarquia esportiva e, portanto, da pirâmide social: o esporte é 'a poesia da hierarquia'. (BROHM, 1978 apud BETTI, 1998, p. 184).

No cenário esportivo atual, o MMA tem adquirido maior visibilidade nos meios de comunicação de massa, tornando-se um grande fenômeno na espetacularização esportiva. Para exemplificar a atuação da mídia na construção dos "heróis esportivos" do MMA, vamos elencar algumas situações vividas por alguns dos principais atletas brasileiros.

Uma programação esportiva de uma rede de TV nacional exibiu, em 2013, uma reportagem sobre o lutador de MMA José Aldo. Na ocasião, a emissora destacou a superação do atleta que nasceu pobre, na cidade de Manaus-AM e migrou para o Rio de Janeiro em busca de melhores condições da vida através das lutas. Durante sua estada na cidade carioca, o atleta enfrentou diversas dificuldades. Sem dinheiro e abrigo, José Aldo passou fome e chegou a dormir na academia em que treinava. Durante a reportagem evidenciou-se que José Aldo foi acolhido por amigos que compartilhavam do mesmo sonho: tornar-se um famoso lutador de MMA. O "Scar Face", como assim é conhecido, venceu as dificuldades para realizar o sonho e tornou-se campeão absoluto da categoria peso-pena, em que já defendeu o cinturão em sete oportunidades, quando enfrentou adversários extremamente difíceis. Considerado, hoje, o melhor lutador da sua categoria no UFC, José Aldo tem sua imagem vinculada a diversos acessórios alusivos ao MMA, desde estampas de camisetas, até bonecos em miniatura ${ }^{8}$.

Porém, a superação não se aplica somente à condição financeira dos atletas. Ela pode ser representada em diversas situações do cotidiano (SANTOS e MEDEIROS, 2009) e a mídia se encarrega em dar ênfase ao atleta que obteve superação em algum momento de sua vida.

No que se refere à superação de problemas no âmbito familiar,um exemplo 
simbólico é o do lutador Vitor Belfort. No início do corrente ano, foi apresentado trechos de uma entrevista com Belfort às vésperas do combate contra Cris Weidman ${ }^{9}$. Além do lutador, amigos e familiares deram depoimentos sobre a sua trajetória de vida. Durante a entrevista, falou-se sobre o drama familiar vivido pelo lutador desde 2004, quando a sua irmã, Priscila Belfort, desapareceu misteriosamente. Belfort afirma ter encontrado nas lutas forças para superar o sofrimento da perda da irmã: "a luta te ajuda a superar seus limites". Em meio ao drama pessoal vivido em 2004, Belfort superou o trauma para seguir adiante em sua carreira e, no mesmo ano, conquistou o título no UFC, ao vencer o lutador estadunidense RandyCouture, e manteve o prestígio e a fama de atleta vencedor, conquistada desde que sagrou-se campeão com apenas 19 anos de idade, tornando-se o mais jovem campeão do referido evento (BELFORT, 2012). Seus feitos no MMA o tornaram mundialmente conhecido como The Phenom (O Fenômeno) ${ }^{10}$.

No que diz respeito a atos heroicos de superação de problemas de saúde, um exemplo que merece destaque foi o drama pessoal vivido por Rodrigo Nogueira, o Minotauro. Em entrevista exibida, no ano de 2012, o lutador brasileiro relatou alguns fatos de sua vida e da sua relação com as artes marciais. O Minotauro evidenciou também um grave acidente na infância quando foi atropelado por um caminhão. $\mathrm{O}$ trágico acontecimento poderia ter deixado sequelas mais graves na vida do atleta, mas, através das artes marciais, ele superou-se para tornar-se, anos mais tarde, um dos mais consagrados lutadores de MMA do mundo. Devido aos seus feitos no esporte, Minotauro é também conhecido como a "Lenda" do MMA e isso reforçou sua popularidade pelos eventos onde lutou, tanto no PRIDE, como no UFC ${ }^{11}$.

Ainda nesse âmbito, outro exemplo emblemático, diz respeito ao lutador Anderson Silva. Em dezembro de 2013, durante a segunda luta que marcou a revanche contra Chris Weidman, Anderson sofreu uma fratura na perna esquerda. $\mathrm{O}$ acidente culminou na sua derrota e no seu afastamento dos octógonos por quase um ano. Esse caso repercutiu na mídia internacional, sobretudo por se tratar de um atleta com um notório histórico de consagração neste esporte ${ }^{12}$. Um ano após ter superado o drama da fratura na perna, o "Spider", como assim é conhecido pelos fãs, retornou ao octógono do UFC. Dessa vez, para enfrentar o lutador estadunidense Nick Diaz. Nos dias que antecederam a luta, uma emissora de TV brasileira, divulgou o duelo nos principais programas esportivos, além de exibir uma série de comerciais e vinhetas sobre a referida luta. Uma das cartadas utilizadas pela emissora foi uma vinheta que mostra Anderson Silva caído no fundo de um poço, sendo atingido por uma série de destroços (representados por jornais impressos,

9 O referido combate foi adiado em virtude de uma lesão sofrida pelo lutador Cris Weidman, às vésperas do evento.

10 Trecho baseado na matéria exibida pelo programa Esporte Espetacular, em 18/01/2015.

11 Trecho baseado na matéria exibida pelo programa Esporte Espetacular, em 23/12/2012.

12 Trecho baseado na matéria exibida pelo programa Esporte Espetacular, em 11/01/2015. 
revistas e aparelhos de TV, noticiando o seu fim) e tendo que "lutar" para "escalar" as paredes e superar diversos obstáculos para, enfim, retornar à superfície ${ }^{13}$. Esse vídeo foi evidenciado repetidas vezes antes da luta, para, não somente divulgar o evento, como para anunciar a superação e o retorno de Anderson Silva ao MMA. Em meio à carência de representantes a "heróis esportivos", desde a morte do Airton Senna, ao que tudo indica, Anderson "Spider" Silva seria o maior candidato ao título e o "chamariz" para aumentar o consumo do MMA e os picos de audiência nas madrugadas de sábado, se não fosse o lamentável episódio de envolvimento na polêmica história do exame antidoping.

Essas e outras histórias de superação no meio esportivo são enfatizadas para que os atletas vencedores tornem-se verdadeiros "heróis", fonte de inspiração para seus admiradores, reforçando o consumo do esporte. Betti (1998) analisa esse processo e critica a mercadorização esportiva sob o viés da espetacularização na superação dos atletas.

Centrados em grandes estrelas do esporte, muitos anúncios valorizam o esforço, a superação de limites, a busca da vitória, o 'altius, citius, fortius', o atleta é a 'fera', o conquistador, o invencível, o guerreiro, o homem livre, o superhomem, o herói (BETTI, 1998, p. 163).

Assim, a mídia evidencia as dificuldades enfrentadas pelo atleta no anonimato e transforma-o num mito ao destacar a fama e o prestígio obtidos na carreira. Pires (2002) nos auxilia a compreender o mecanismo utilizado pela mídia neste processo:

Para reforçar a admiração e a identidade do público para com estes novos heróis, suas biografias são reconstruídas com o auxílio de especialistas em marketing, em que um dos principais cuidados é evidenciar as diferenças sócio-econômicas entre a origem e o atual status do ídolo.[...] aspectos pintados com tintas fortes para contrastar com as benesses alcançadas na nova condição social, simbolizadas pela aquisição de confortáveis residências em áreas restritas, carros importados e outros sinais evidentes de riqueza (p. 106).

Outro mecanismo da indústria midiática presente na construção dos "heróis esportivos" do MMA é o sensacionalismo na veiculação de informações sobre fatos vividos pelos atletas. Representado como um herói ao final do processo, o atleta será o "chamariz" para incentivar o consumo do esporte.

Nesse contexto, percebe-se a relevância dada ao esporte pela indústria midiática, com destaque para o sensacionalismo dos jornais e programas esportivos, atribuindo-lhe diversas características, dentre elas o esporte espetáculo como possibilidade de ascensão social, mediante a idolatria e exposição dos atletas 'heróis', valorizados pelos feitos no meio esportivo ou pelo prestígio da fama e do dinheiro. [...] a mídia utiliza a figura do atleta campeão como 'protótipo' de sucesso para incutir sua ideologia na mente dos indivíduos (MIRANDA FILHO e SANTOS, 2014b, p. 867).

13 O referido vídeo foi uma produção da cervejaria Budweiser, uma das patrocinadoras do UFC e do lutador brasileiro. 
A fama e a riqueza dão contornos míticos ao atleta, tornando-o um sujeito admirável e ainda mais especial por ter sido capaz de realizar um feito notável e pouco provável para a maioria dos indivíduos.

[...] o Capitalismo impõe que as pessoas estejam sempre buscando a melhoria de sua situação financeira. Sendo assim, o papel da mídia é mostrar e idolatrar alguns pouquíssimos atletas que conseguem obter sucesso através do esporte e fazer com que estes passem a servir como modelos para outros milhões de pessoas que tentarão em vão este mesmo sucesso (LEITE, 2008, p. 03).

Portanto, é nessa perspectiva alienante que a mídia constrói o estereótipo do "herói esportivo" a ser seguido pelo povo: uma pseudo necessidade criada pela indústria cultural e que será disseminada pelos meios de comunicação de massa. O "herói esportivo" será aquele atleta transformado num símbolo das necessidades das massas, uma espécie de "libertação" ou fuga de prováveis frustrações e insucessos; a "satisfação na sua própria negação" (ADORNO e HORKHEIMER, 1985).

\section{CONSIDERAÇÕES FINAIS}

Este estudo teve como objetivo apresentar considerações sobre alguns mecanismos utilizados pela indústria midiática na construção dos "heróis esportivos" do $M M A$, visando a compreender a contribuição desse processo no consumo deste esporte, sem pretensão de esgotar tal temática.

Em síntese, a partir das discussões empreendidas neste texto, é possível compreender que os meios de comunicação de massa, em especial a mídia televisiva, se utilizam de mecanismos que mexem com a imaginação e a emoção do telespectador, tais como, espetacularização, uso de marketing especializado e sensacionalismo, presentes na construção midiática dos "heróis esportivos" do MMA. Processo este que tem contribuído, significativamente, no consumo alienado de mercadorias alusivas ao MMA e na sua popularização em nossa sociedade.

\section{REFERÊNCIAS}

ABAGGNANO, N. Dicionário de Filosofia.

Tradução da $1^{\text {a }}$ edição brasileira coordenada e revista por Alfredo Bossi; revisão da tradução e tradução dos novos textos de Ivone Castilho Benedetti. $5^{\text {a }}$ Ed. - São Paulo: Martins Fontes, 2007.

ADORNO, T. W.; HORKHEIMER, M. Dialética do esclarecimento: fragmentos filosóficos. Tradução: Guido Antônio de Almeida. Rio de Janeiro: Jorge Zahar ED, 1985.

ALVAREZ, F. de L.; MARQUES, J. C.Breves Questionamentos Sobre o Fenômeno Midiático do MMA - Mixed Martial Arts(Artes Marciais Mistas): uma Proposta de Estudo. In: Anais [Da] Intercom - Sociedade Brasileira de Estudos Interdisciplinares da Comunicação. XXXIV Congresso Brasileiro de Ciências da Comunicação - Recife, PE - 2 a 6 de setembro de 2011.

BELFORT, $V$. Lições de garra, fé e sucesso. Rio de janeiro: Thomas Nelson Brasil, 2012.

BETTI, M.A Janela de Vidro: esporte, televisão e educação física. Campinas: Papirus, 1998.

. Corpo, cultura, mídias e educação

física: novas relações no mundo 
contemporâneo.LecturasEducación

Física y Deportes. Revista Digital (Buenos Aires), ano 10, n. 79, dez. 2004.

BRACHT, V.Sociologia crítica do esporte: uma introdução. 3.ed. - ljuí: Ed. Unijuí, 2005.

LEITE, W. S. S. Ilusão em massa: o papel da mídia no esporte.LecturasEducación Física y Deportes. Revista Digital (Buenos Aires), ano 13, n. 123, Ago. 2008.

MARTINEZ, A. Heróis do MMA. Parte 1. Rio de janeiro: Tatame publicações, 2012 (série guerreiros imortais).

MIRANDA FILHO, V. F.; SANTOS, I. S. P. dos. A influência da mídia na mercadorização do MMA. LecturasEducación Física y Deportes (Buenos Aires), v. 18, p. 1-9, 2014a. - Mídia, mercadorização esportiva

e o movimento de popularização do
MMA. Pensar a Prática (Online), v. 17, p. 865-877, $2014 \mathrm{~b}$.

PELLANDA, F. A.; PASTRE, T. F. de L.; AUGUSTO, V. N.O Processo de Desportivização do MMA. $1^{\circ}$ ENCONTRO DA ALESDE "Esporte na América Latina: atualidade e perspectivas" UFPR - Curitiba - Paraná - Brasil, 2008.

PIRES, G. De L.A Educação Física e o Discurso Midiático: abordagem críticoemancipatória. ljuí: Ed. Unijuí, 2002. $-336 \mathrm{p}$.

RUBIO, K. O atleta e o mito do herói: o imaginário esportivo contemporâneo. São Paulo: Casa do psicólogo, 2001.

SANTOS, D. S.; MEDEIROS, A. G. A. O discurso midiático e as representações sociais do esporte: o atleta como modelo de comportamento. Pensar a Prática (Online), v. 12, p. 1-11, 2009.

CONSIDERATIONS ON THE MEDIA AND “SPORTS HEROES” OF MIXED MARTIAL ARTS

\begin{abstract}
The text aims to present some considerations about mechanisms used by the media industry in the construction of "sports heroes" of the Mixed Martia IArts (MMA). Therefore, there was a theoretical study and highlighted a few examples of situations experienced by Brazilian MMA athletes to discuss such mechanisms. Thus, it is understood that the sporting spectacle, the use of specialized marketing and sensationalism in the dissemination of information about the lives of these athletes are some of the mechanisms used by the media in the construction of MMA heroes. We conclude that this is one of the most effective strategies to transform the MMA a popular phenomenon, encouraging their consumption sold in Brazilian society.
\end{abstract}

Keywords: Media; MMA; Sporting Heroes 
CONSIDERACIONES SOBRE LOS MEDIOS DE COMUNICACIÓN Y “HÉROES DEPORTIVOS" DE MIXED MARTIAL ARTS

\section{RESUMEN}

El texto tiene como objetivo presentar algunas consideraciones sobre los mecanismos utilizados por la industria de los medios en la construcción de los "héroes del deporte" de la Mixta Martia Larts (MMA). Por lo tanto, hubo un estudio teórico y destacó algunos ejemplos de situaciones vividas por los atletas de MMA de Brasil para discutir este tipo de mecanismos. Por lo tanto, se entiende que el espectáculo deportivo, el uso del marketing especializado y el sensacionalismo en la difusión de información sobre la vida de estos atletas son algunos de los mecanismos utilizados por los medios de comunicación en la construcción de los héroes de MMA. Llegamos a la conclusión de que esta es una de las estrategias más eficaces para transformar el MMA en un fenómeno popular, fomentar su consumo vendida en la sociedad brasileña.

Palabras clave: Medios de Comunicación; MMA; Héroes Deportivos

Recebido em: fevereiro/2015 Aprovado em: abril/2015 